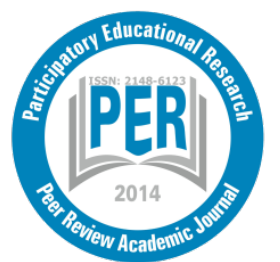

Participatory Educational Research (PER)

Vol. 7(2), pp. 80-101, August 2020

Available online at http://www.perjournal.com

ISSN: 2148-6123

http://dx.doi.org/10.17275/per.20.21.7.2

\title{
The Institutionalization of Ethics in Schools: A Qualitative Research on Teachers
}

\author{
Mehmet Hilmi KOÇ* \\ Sabahattin Zaim University, Faculty of Education, Istanbul, Turkey \\ ORCID: 0000-0001-6259-173X
}

\begin{tabular}{|c|c|}
\hline \multicolumn{2}{|c|}{$\begin{array}{c}\text { Tuncer FİDAN } \\
\text { Mehmet Akif Ersoy University, Office of Internal Audits, Internal Audit, Burdur, Turkey } \\
\text { ORCID: 0000-0002-9954-1004 }\end{array}$} \\
\hline Article history & This study aims to reveal teachers' views on the institutionalization of \\
\hline $\begin{array}{l}\text { Received: } \\
10.02 .2020\end{array}$ & $\begin{array}{l}\text { ethical and unethical behaviors in school settings. This is a } \\
\text { phenomenological study, one of the qualitative research designs. }\end{array}$ \\
\hline $\begin{array}{l}\text { Received in revised form: } \\
10.04 .2020\end{array}$ & $\begin{array}{l}\text { Purposeful sampling method was used in this study. The study group } \\
\text { consisted of } 20 \text { teachers working in schools in Istanbul. A semi- } \\
\text { structured interview form was developed to collect data. A content }\end{array}$ \\
\hline $\begin{array}{l}\text { Accepted: } \\
11.04 .2020\end{array}$ & $\begin{array}{l}\text { analysis was conducted to analyze the contents of the interviews. Based } \\
\text { on the findings, it can be said that there are no systematic efforts to }\end{array}$ \\
\hline & institutionalize ethics in schools. One of the most significant results of \\
\hline $\begin{array}{l}\text { institutionalization of ethics; } \\
\text { explicit institutionalization; } \\
\text { implicit institutionalization; } \\
\text { ethical consensus; unethicality }\end{array}$ & $\begin{array}{l}\text { this study was that there was a tendency to respond negatively or to not } \\
\text { respond to ethical behaviors in schools, while there was no institutional } \\
\text { response to unethical behaviors. Unethicality, rather than ethicality, } \\
\text { might be expected to institutionalize in schools where teachers have } \\
\text { difficulties for their ethical behaviors, but do not have any problems for } \\
\text { their unethical behaviors. In such conditions, teachers predominantly } \\
\text { make individual efforts to act ethically since they are mostly devoid of } \\
\text { the support of a strong institutional environment encouraging ethical } \\
\text { behaviors. Furthermore, according to the participants, there was no } \\
\text { ethical consensus on what should be done on facing unethical behaviors. } \\
\text { The results of this study indicated that there could be a tendency towards } \\
\text { the institutionalization of unethicality rather than ethicality in schools. A } \\
\text { formal structure, such as an ethical committee, which can control the } \\
\text { application of ethical principles and codes and evaluate change } \\
\text { requirements in this process, is required to hinder the institutionalization } \\
\text { of unethicality in schools. Besides, there are also certain strategies that } \\
\text { administrators and teachers can use to reverse this tendency. }\end{array}$ \\
\hline
\end{tabular}

\section{Introduction}

Globalization, effects of information technologies, increasing competition and scarce resources have changed people's views on what a good organization should be like and how it should be managed well. The increasing complexity and rapid changes have weakened formal rules and organizational borders, and therefore highlighted values-based management

\footnotetext{
* Correspondence: kocmehmethilmi@gmail.com_Tel:5058196022
} 
strategies, which can get people with different pasts and views to work for the same purpose. At this point, business ethics has turned into a strategic factor protecting organizations, which operate in environments difficult to control, from undesirable disasters. Ethical culture can establish trust inside and outside organizations, and trust in turn can encourage employees to take risks at acceptable levels. Thus, organizations can adapt to changes without making much effort to control people and without giving up their organizational integrity (Koonmee, Singhapakdi, Virakul \& Lee, 2010).

However, unethicality can still be seen despite the advantages ethics can provide to organizations. One of the methods administrators adopt to hinder unethicality and to encourage employees to engage in ethical actions is institutionalization. For example, structural measures for institutionalization, such as establishing ethical committees and ombudsmen, issuing ethical regulations and publishing ethical bulletins regularly, are frequently used in organizations. Such measures can provide advantages to organizations by creating positive images, especially in the eyes of external stakeholders. Furthermore, they can positively influence relations, particularly with public organizations that have supervision authority over ethical issues; however, when such formal measures do not lead to the formation of an ethical culture- that is to say, when ethical values are not internalized by employees- the probability of the emergence of unethical actions increases (Vitell \& Singhapakdi, 2008).

The increasing prevalence of unethical behaviors in educational organizations and heated discussions over these behaviors in the public have brought ethical issues in educational settings in question. In addition, describing schools only as arenas where teachers compete to attain their career objectives can be inadequate in analyzing the complexity of political relations within schools; because the social actors that should be persuaded to attain personal career objectives may not be limited to other teachers and administrators. Factionalism on the basis of such factors as ideological differences, gender, educational status, union membership, professional experience and administrative experience are also a part of school culture (Ball, 2012; Blase, 2000). Issues, such as hidden agenda and organizational factionalism, are among the important issues of informal communication in schools due to such diversity. Besides, increasing complexity within schools can cause different stakeholders to have different values about the quality of ethical behaviors and can make it difficult to reach a general consensus about ethics (Datnow, 2013).

In order to institutionalize ethics and prevent misconducts in schools in Turkey, the Ministry of National Education (MoNE) has made a series of legal regulations, such as "Law on the Establishment of the Ethics Committee for Public Officials and Amendments to Some Laws (Law No. 5176)", "Regulation on the Principles of Ethical Behavior for Public Officials, and Rules and Procedures of Application to the Committees", "Procedures and Principles regarding Works of Ethics Committee of MoNE" and "Ministerial Circular of MoNE on Ethics". In accordance with these arrangements, ethical committees were established in the central organization of MoNE and provincial national education directorates to deal with ethical issues encountered in schools. Moreover, every novice teacher is obliged to sign an ethical contract with MoNE to acknowledge principles prescribed by professional ethics and legal regulations on ethics. There are studies in the literature focusing on the congruence of teacher behaviors with professional ethics (Toprakçı, Bozpolat \& Buldur, 2010) and unethical behaviors of teachers (Altınkurt \& Y1lmaz, 2011); however, studies on whether these principles have really been internalized by teachers and administrators, and whether they are institutionalized in schools are extremely rare. Therefore, the aim of this study is to examine the institutionalization of ethical and unethical behaviors in schools and the factors influential in this process. 
Examining the institutionalization of ethics in schools can reveal the extent to which legal regulations on ethics are internalized by teachers and have become an integral part of school cultures. Also, it can help to uncover the power of informal relations in schools. Additionally, the efforts made by administrators and teachers for the institutionalization of ethics and the obstacles they encounter in this process can also be revealed. We argue that such activities can also give clues about what should be done for the institutionalization of ethics in schools.

\section{The Institutionalization of Ethical and Unethical Behaviors}

It can be argued that the most fundamental strategy used to struggle with unethicality in educational organizations is to institutionalize ethical behaviors. The institutionalization of ethics can be defined as making ethical values an inseparable component of decision-making processes in an organization. The institutionalization of ethics can occur explicitly and implicitly (Singhapakdi \& Vitell, 2007).

\section{Explicit Institutionalization}

Explicit institutionalization is the expression of the ethical behaviors, expected of employees, in formal ways and without any vagueness. Ethical behaviors are to be turned into formal rules and structures in the form of ethical codes, policy documents, orientation programs and ethical committees for such type of institutionalization. Those rules and structures aim to determine what an ethical behavior is and how ethical rules are implemented in organizations and thus to inculcate ethical values into employees through socialization (Lee, Grace, Sirgy, Singhapakdi \& Lucianetti, 2018).

\section{Implicit Institutionalization}

In implicit institutionalization, the ethical behaviors, expected of employees, are implied instead of directly expressed and are understood as vital for organizations. Organizations need to create a climate that encourages ethical behaviors for such institutionalization. Ethics becomes an inseparable part of organizational culture through implicit institutionalization (Singhapakdi \& Vitell, 2007). In other words, employees consider ethical behaviors as essential for the structure and functioning of an organization. For example, in organizations, where a high level of implicit institutionalization is achieved, all the administrators are expected to display high professionalism, honesty and integrity. Performance systems, where ethical leadership, ethical work environment and ethical behaviors are rewarded, are frequently seen in such organizations (Lee et al., 2018).

There are studies in the literature indicating that explicit institutionalization is the antecedent of implicit institutionalization. Therefore, the process of explicit institutionalization should primarily be completed in schools. Furthermore, there are studies reporting that the life quality, job satisfaction and commitment of employees increase as the level of implicit institutionalization of ethics increases (Marta et al., 2013). Implicit institutionalization can also accelerate the decision-making processes of administrators by minimizing the risks stemming from unethical decisions and can facilitate employees' approval of managerial decisions (Trevino, 1986).

On the other hand, a conceptualization or classification regarding the institutionalization of unethicality has not been developed yet, since it refers to situations that emerge due to failures in the institutionalization process of ethics or that cannot be eliminated by this process (Hosmer, 1987; Lee et al., 2018). Unethical behaviors can be defined as actions against the law or morally unacceptable to the majority of the society. Unethicality involves behaviors contrary to ethical norms and standards such as theft, deception and lying. The institutionalization of unethicality 
occurs with the repetition and routinization of such behaviors over time (Gino \& Bazerman, 2009).

It can be said that the institutionalization of unethicality is a process emerging from the failures, incompleteness or nonexistence of efforts towards the institutionalization of ethics. The institutionalization of unethical behaviors might lead to permanent beliefs that organizational practices are distrustful (Long \& Rao, 1995). Even though it facilitates employees to attain their political goals in the short-term, it can negatively influence the functioning of an organization in the long-term by causing high turnover intentions and social exclusion (Thau, Derfler-Rozin, Pitesa, Mitchell \& Pillutla, 2015).

\section{Factors Influencing the Institutionalization of Ethical and Unethical Behaviors}

Factors influencing the institutionalization of ethical and unethical behaviors can be analyzed using the social learning theory. According to social learning theory, learning takes places within a social context through mechanisms, such as imitation and modeling. That is to say, the institutionalization of ethics arises from complex interactions between individuals and their environment (Reed et al., 2010). Furthermore, the differential association theory can be used as a framework of portraying particularly the institutionalization of unethical behaviors. According to this theory, individuals acquire values, attitudes and motives for unethical conducts through interaction with others, especially the proximal members of an organization (Ashforth \& Anand, 2003). In this respect, following Trevino, Weaver and Reynolds (2006) and Ashforth and Anand (2003), we argue that factors influential in the institutionalization of ethical and of unethical behaviors can be classified in two groups as "individual factors" and "organizational factors".

\section{Individual Factors}

These involve intrinsic components, such as cognitive, affective and identity-related factors. This section discusses these factors respectively.

1. Cognitive factors: Cognitive factors contain (a) moral awareness, (b) moral judgement, (c) moral disengagement and (d) cognitive biases. The first stage of ethical decision-making process is to have (a) moral awareness - in other words, the ability to identify the moral problem. Individuals need to be aware of the existence of moral standards or principles related to the situation they face in order to identify moral problems. While high moral awareness supports the emergence of ethical behaviors, the lack thereof can lead to the emergence of unethical behaviors and to the institutionalization of such behaviors if they do not come across any barriers (Trevino et al., 2006).

(b) Moral judgement, on the other hand, is heavily based on Kohlberg's (1969) theory of moral development. The process of moral judgement generally starts as soon as individuals have moral awareness. Individuals' judgements about what is right and what is wrong are extremely open to external effects. Therefore, organizational norms, co-worker behaviors, leadership, punishment/reward systems, organizational climate and culture have great effects on employees' judgements about right and wrong (Trevino \& Weaver, 2003). While individuals with high moral development are not open to environmental effects in their decision-making, those with lower moral development are likely to shape their judgements about right and wrong according to environmental effects. Besides, environmental effects decrease in parallel to the rise in age and education level. The quality of unethical events is also influential in individual 
judgements. For example, physical harms draw more reactions than psychological and economic harms (Trevino, 1986; Trevino et al., 2006).

The fact that moral judgements are so open to external effects has caused research on how individuals' low information processing capacity influence their moral judgements (Trevino et al., 2006). Concepts such as (c) moral disengagement and (d) cognitive bias are the focal points of such research. According to Bandura (1999), for instance, people are usually directed by their personal ethical standards. When activated, those standards take on self-regulating roles leading individuals to good behaviors. For this reason, it can be said that ethical behaviors are regulated through internal self-regulatory mechanisms which make people avoid self-sanctions they mostly apply on themselves. On the other hand, people often disengage from those internal self-regulatory mechanisms. Moral disengagement makes individuals free from internal selfsanctions and the feeling of guilt that stem from violating ethical rules (Bandura, 1999).

Three categories of moral disengagement are defined by Bandura (1999). The first is cognitive reconstruction of a behavior. Reconstruction of a behavior occurs in the form of legitimizing unethical actions, understating the action by using different words (for example using 'losses' instead of 'deaths') and making advantaged comparisons to state an activity as less serious than it is. The second moral disengagement mechanism is reducing people's roles in harmful behaviors. It occurs through displacement of responsibility, diffusion of responsibility and distorting of consequences. The third mechanism is focusing on unfavorable behaviors of a target person. It occurs in the form of dehumanizing and blaming. The victims of those moral disengagement mechanisms are particularly people from other moral groups (Bandura, 1999).

Another factor that affects the process of moral judgement is (d) cognitive bias. Cognitive biases are the factors by which individuals are unwittingly influenced in decision-making processes. Pragmatism is among such biases, because there are studies demonstrating that employees attach more importance to the level of benefits of the yielded results than the rightness or wrongness of a decision. As benefits relatively increases, the judgements about right and wrong can also change (Kahneman, 2003). In addition, people act according to wrong assumptions about weak social groups such as women and minorities. Generally, less care is taken with the congruity of actions to ethical values when it comes to weak social groups. Furthermore, people usually have high self-confidence in ethical issues and consider themselves more ethical than they really are (Cook \& Glass, 2014). Finally, employees are unwittingly inclined to adopt unethical actions that have already been institutionalized in their work environment (Long \& Rao, 1995).

2. Affective factors: Affective factors involve trait-based positive or negative feelings and emotional reactions to events. Feelings, such as guilt, shame and empathy, take on important roles especially in moral issues. Guilt represents regrets felt after misdoing something. Shame is related to the self and identity. It is an individual's self-devaluation and self-condemnation. Guilt is more closely associated with empathetic behaviors, making apology and restitution. Individuals' probability to display ethical behaviors or to react to unethical behaviors increases as emotional factors gain strength. However, emotional factors contribute to the dissemination and institutionalization of unethical behaviors when they are weakened (Eisenberg, 2000; (Trevino et al., 2006)).

3. Identity-related factors: Individuals' moral development is associated with the formation of their identities; because moral judgements leading to moral behaviors is related not only to individuals' values, but also to the extent those values become a part of their identities. If being 
moral is one of the fundamental properties defining an individuals' personalities, the probability of moral judgements leading to ethical behaviors rises, and unethical behaviors cause cognitive inconsistency and emotional disturbance. Otherwise, the unethical behaviors are considered as usual and routine (Blasi, 1999).

\section{Organizational Factors}

Organizational factors are related to the work environment shaping ethical or unethical behaviors, because the degree of ethicality or unethicality of the work environment can shape employees' actions by influencing their cognitive processes. Organizational factors can be listed as organizational culture, ethical climate, leadership, punishment/reward system, locus of control, the existence of different ethical groups and language (Booth \& Schulz, 2004; Trevino, 1986; Trevino et al., 2006).

1. Organizational culture: Organizations can enable new members to acquire standard ways of thinking and acting, which have been accepted by overall members, through socialization. If organizations are isolated from the rest of the society, they can form a kind of moral micro universe. In such cases, employees can consider organizational interests equal to those of general society without questioning. What is more, unethical behaviors can be regarded as usual, and employees can engage in such behaviors without questioning. In organizations, that could not create such an isolated culture, employees can clearly be pressurized to act unethically particularly to attain organizational goals. In some cases, employees can have role conflicts and see unethical behaviors as a way out (Trevino et al., 2006). On the other hand, vision and mission statements highlighting ethical values, the presence of ethical training programs and written ethical rules fairly applied to all organizational members can incorporate ethics into organizational cultures (Booth \& Schulz, 2004; Singhapakdi \& Vitell, 2007).

2. Ethical climate: Ethical climate is the shared perceptions of organizational members regarding the criteria and focus of ethical inquiries. As the power of ethical climate increases, expectations that employees will display ethical behaviors also increase. When the climate gets weaker or ethical values are diversified to the extent that sub-climates rise, however, the consequence is the institutionalization of unethical behaviors. Leadership, punishment/reward system, the existence of different ethical groups, locus of control and language are important in the formation of ethical climate (Chiu, 2003; Fritzsche, 2000).

3. Leadership: Employees generally pay attention to how leaders implement ethical rules since ethical leaders are expected to enforce those rules fairly and carefully. As leaders display ethical behaviors, employees react in identical ways. On the other hand, unethical leadership behaviors can function as one of the strongest mechanisms of the institutionalization of unethicality. Furthermore, as a leader's authoritarianism level rises, employees' probability to display unethical behaviors also increase (Brown \& Trevino, 2006).

4. Punishment/reward system: Another issue directly associated with ethical and unethical behaviors is the punishment/reward system. For example, unethical behaviors are institutionalized when they are rewarded. On the other hand, the same result cannot be achieved when ethical behaviors are rewarded. Even the intrinsic value of an ethical behavior diminishes when economic incentives are used. However, at least, employees do not want to be punished for their ethical behaviors. The fair enforcement of ethical rules and punishment/reward system is the general expectation by employees. They also expect that there should be a parallelism between unethical behaviors and penalties, since inflicting little punishment to a serious unethical behavior may cause more harm to the ethical climate of the organization than 
overlooking such misconducts (Brown \& Trevino, 2006; Trevino \& Weaver, 2003).

5. Locus of control: The concept of locus of control is closely associated with ethical behaviors. The probability of moral judgements' leading to ethical behaviors rises in work environments where the majority of employees have internal locus of control. On the contrary, the probability of institutionalization of unethical behaviors rises as the number of employees with external locus of control increases (Chiu, 2003).

6. The existence of different ethical groups: Organizations are not composed only of individuals. Individuals sometimes come together on the basis of their interests and personal traits and form groups. Individuals can attach more importance to the norms of groups, they have a sense of belonging for, than organizational rules, particularly in organizations with weak cultures. The power of a group can pave the way for behaviors that one may not dare to display individually. Besides, group norms can establish ethical sub-groups and lead to the inclusion of normally unethical actions into moral boundaries when they gain enough strength (Booth \& Schulz, 2004).

7. Language: Language, dominantly used in an organization, can encourage ethical or unethical behaviors. The more the employees have the opportunity to speak about ethical issues, the higher the probability of displaying ethical behaviors. On the other hand, moral silence supports unethical behaviors (Trevino et al., 2006).

Individual and organizational factors can contribute to the institutionalization of ethics when they have positive effects, whereas they can contribute to the institutionalization of unethical behaviors when they have negative effects or inadequate effects on the individuals and organizational environment (Trevino et al., 2006). These factors are summarized in Table 1.

Table 1. Factors Influencing the Institutionalization of Ethical and Unethical Behaviors

\section{Individual Factors}

$\begin{array}{ll} & \text { (a) Moral Awareness: Ability to identify the moral problem } \\ & \text { (b) Moral Judgement: Ability to make judgements about right and wrong } \\ \text { 1. Cognitive Factors: } & \text { (c) Moral Disengagement: Disengagement from internal moral self-regulatory } \\ \text { mechanisms to avoid feeling of guilt } \\ \text { (d) Cognitive Biases: Factors by which individuals are unwittingly influenced } \\ \text { in decision-making processes }\end{array}$

2. Affective Factors: Trait-based positive or negative feelings and emotional reactions to events

3. Identity-Related Factors: The extent that moral values become an integral part of one's identity

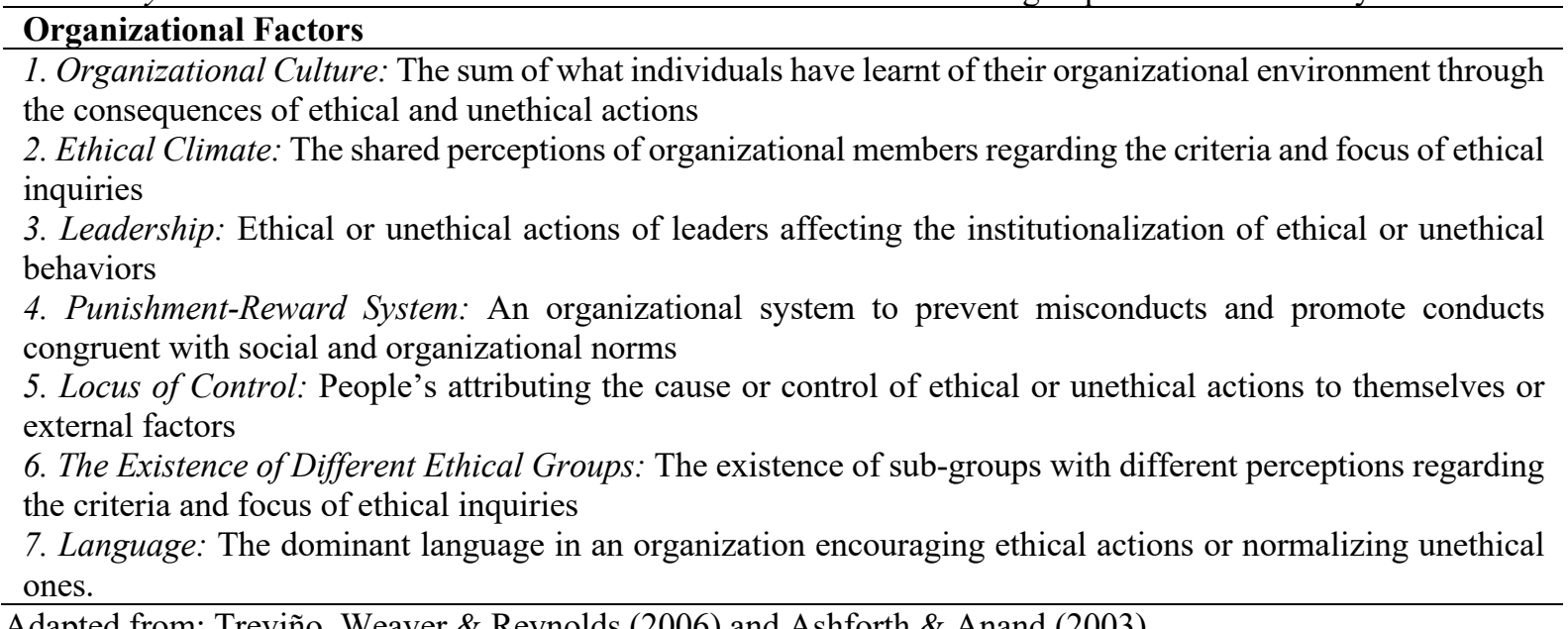

Adapted from: Treviño, Weaver \& Reynolds (2006) and Ashforth \& Anand (2003) 
As seen in Table 1, the institutionalization of ethical or unethical behaviors is the result of the complex interaction process between individual and organizational factors. Without the support of organizational factors, ethical behaviors, driven predominantly by individual factors, are likely to wither before institutionalized. Without the help of individual factors, organizational factors are unlikely to cover all the grey areas where the decisions regarding what is right or wrong are mainly contingent upon individuals' reasoning. Accordingly, the institutionalization of ethics requires both implicit and explicit processes while the institutionalization of unethical behaviors is the result of the lack, weakness or dysfunction of individual and organizational factors (Ashforth \& Anand, 2003; Singhapakdi \& Vitell, 2007).

In the light of the above discussion, this study aims to reveal the views of teachers working in schools operated by the Ministry of National Education (MoNE) on the institutionalization of ethical and unethical behaviors. Hence, it seeks answers to the following questions:

(1) What are the factors facilitating and hindering the institutionalization of ethical behaviors in schools?

(2) What are the factors leading teachers to behave ethically and unethically in schools?

(3) What kind of reactions do ethical and unethical behaviors arouse in schools?

(4) How is consensus on ethical issues reached in schools?

\section{Method}

Research design, study group, data collection tools and data analysis are described under this heading.

\section{Research Design}

This qualitative study aimed to reveal the participants' views on the institutionalization of ethical and unethical behaviors in schools. Qualitative studies aim to provide understanding and sensitivity regarding human experiences to readers (Knafl \& Howard, 1984). It is possible through qualitative studies to reveal how individuals interpret and make sense of a phenomenon (Denzin \& Lincoln, 2005).

This study uses the phenomenological research method to describe the participants' experiences about the institutionalization of ethical and unethical behaviours. Phenomenological design focuses on the phenomena, such as events, experiences, perceptions and situations, of which we are aware but about which we do not have in depth and detailed comprehension (Y1ldirım \& Şimşek, 2011). The purpose of phenomenological studies is to question the experiences about a phenomenon and to get into the essence of the experiences (Balc1, 2013). In other words, the purpose is to reduce individual experiences to phenomena to portray the nature of universal reality, events or entities (Creswell, 2007). This study aims to demonstrate teachers' perceptions and experiences about the institutionalization of ethics in educational organizations using a phenomenological design. This design was preferred, because it can be effective in reflecting experiences and interpretations fairly and as free from researchers' prejudices (Tufford \& Newman, 2012). Phenomenological design may also be useful in understanding the shared experiences of several individuals about the same phenomenon. The research and interpretation processes were conducted through bracketing participants' personal experiences as much as possible. The study group consisted of participants who experienced the phenomenon. The data were collected through interviews with the participants. Open-ended questions were developed to reveal the participants' experiences and perceptions about the phenomenon. 


\section{Study Group}

The study group was composed of 20 teachers working in the Beyoğlu district of Istanbul in the 2019-2020 academic year. Optimal data could be collected thanks to the size of the study group, and data saturation could therefore be obtained in categories. Data saturation causes repetition of data in categories. Repetitions indicate the comprehensiveness and completeness of the research (Morse, 1991). Maximum variation, one of the purposeful sampling strategies, was used in this study. Thus, teachers teaching in four types of schoolsprimary school, secondary school, Anatolian high school and vocational high school- were included in the study group. The condition of data variation- one of the criteria for credibility in qualitative research- was satisfied in this way (Arastaman, Öztürk Fidan \& Fidan, 2018). Table 2 shows the demographic information of the participants.

Table 2. Demographic Information of the Participants

\begin{tabular}{lllll}
\hline Rank No & Nickname & Gender & $\begin{array}{l}\text { Years of } \\
\text { teaching }\end{array}$ & Branch \\
\hline 1 & PS1 & Female & 19 & Primary school teacher \\
2 & PS2 & Female & 2 & $\begin{array}{l}\text { Primary school teacher } \\
\text { Primary school teacher } \\
3\end{array}$ \\
4 & PS3 & Male & 17 & Primary school teacher \\
5 & PS4 & Male & 13 & Primary school teacher \\
6 & PS5 & Male & 12 & Primary school teacher \\
7 & PS6 & Female & 13 & Foreign language teacher \\
8 & AHS7 & Female & 6 & Mathematics teacher \\
9 & AHS8 & Male & 18 & History teacher \\
10 & AHS9 & Female & 12 & Religious culture teacher \\
11 & AHS10 & Female & 12 & Mathematics teacher \\
12 & SS11 & Male & 6 & Informatics teacher \\
13 & SS12 & Female & 9 & Phys. Ed. Teacher \\
14 & SS13 & Female & 4 & Science teacher \\
15 & SS14 & Male & 5 & Religious culture teacher \\
16 & SS15 & Male & 15 & Physics teacher \\
17 & VHS16 & Female & 27 & Vocational course teacher \\
18 & VHS17 & Female & 29 & Vocational course teacher \\
19 & VHS18 & Female & 7 & Vocational course teacher \\
20 & VHS19 & Female & 18 & Vocational course teacher \\
\hline
\end{tabular}

As clear from Table 2, 13 of the participants were female, while seven of them were male. Four participants had 1-5 year teaching experience, whereas four had 6-10 year, six had 11-15 year, four had 16-20 year teaching experience and two had more than 20 years of teaching experience. Six participants taught in primary schools, four taught in secondary schools, five in Anatolian high schools and five in vocational high schools. No information about participants' identities was given to preserve anonymity and confidentiality. Instead, the participants were given nicknames (e.g. PS3: primary school teacher 3; ASS10: Anatolian high school teacher 10; SS15: secondary school teacher 15; VHS18: vocational high school teacher 18).

\section{Data Collection}

A semi-structured interview form was prepared by reviewing the previous studies on the institutionalization of ethical and unethical behaviors, making field visits to schools and interviewing teachers working at different levels of schools. The interview form consisted of two sections. In the first section, there were questions about demographic variables, such as gender, school type and teaching branch. The second section consisted of open-ended questions, such as "What are the factors facilitating or hampering the implementation of legal regulations 
on ethics in your school? Please explain by examples." and "Has a consensus been reached on what right and wrong behaviors are in your school? If so, how? If not, why?". All the interviews were voice recorded with the consent of the participants. Repetitive questioning was conducted to make sure that sufficient data were collected. The questions were re-asked by paraphrasing when they were not understood by the participants (Shenton, 2004). The interviews lasted for 40-60 minutes. The participants were asked to check the records of the interviews to obtain their approval, which is one of the criteria for credibility in qualitative research. Thus, whether or not there was a match between the participants' experiences and their words could be examined (Guba, 1981).

\section{Data Analysis}

Content analysis was conducted to analyze the data collected. According to Babbie (2006), content analysis is the process of coding and is conducted to convert raw data into standard forms. In this direction, the raw data were converted into texts, and coding categories were derived from texts. Afterwards, themes were identified from the coding categories. During this process, the common points in the text content were detected and divided into themes (Babbie, 2006). It is pointed out that peer scrutiny increases the credibility of a qualitative study (Arastaman, Öztürk Fidan \& Fidan, 2018). Therefore, two academics from the educational administration field were consulted for their views to determine the appropriateness of the method and research design to the phenomenon to be studied and to check the relevance of codes and themes to participants' interpretations. Additionally, the inter-coder agreement technique was also used to test internal consistency. This technique relies on the coding of two researchers using the same data set. In this way, researchers could develop a shared understanding about the meanings of codes and how codes were derived from data pieces. The level of the inter-coder agreement is supposed to be above $80 \%$ and the agreement was found to be $86 \%$ in this study (Miles \& Huberman, 1994).

\section{Findings}

The findings are presented below in accordance with the themes derived from research questions. They are listed as the institutionalization of ethics in schools, factors causing teachers to behave ethically and unethically, reactions to ethical and unethical behaviors and ethical consensus.

\section{Findings for the Institutionalization of Ethics in Schools}

The sub-themes and frequencies for the theme of the institutionalization of ethics in schools are shown in Figure 1 below. An examination of Figure 1 makes it clear that efforts made for the institutionalization of ethics in schools are inadequate. The ethics is institutionalized in two forms as explicit and implicit. Primarily explicit institutionalization efforts should be completed to achieve the institutionalization of ethics. Yet, the findings demonstrated that there was no systematic effort to institutionalize ethics in the schools of the participants. It is obvious that the legal regulations enforced by MoNE to create ethical cultures in schools have limited effects on schools and employees. Almost all the participants stated that they did not read the legal texts concerning ethics issued by MoNE and did not have enough knowledge on ethics. 


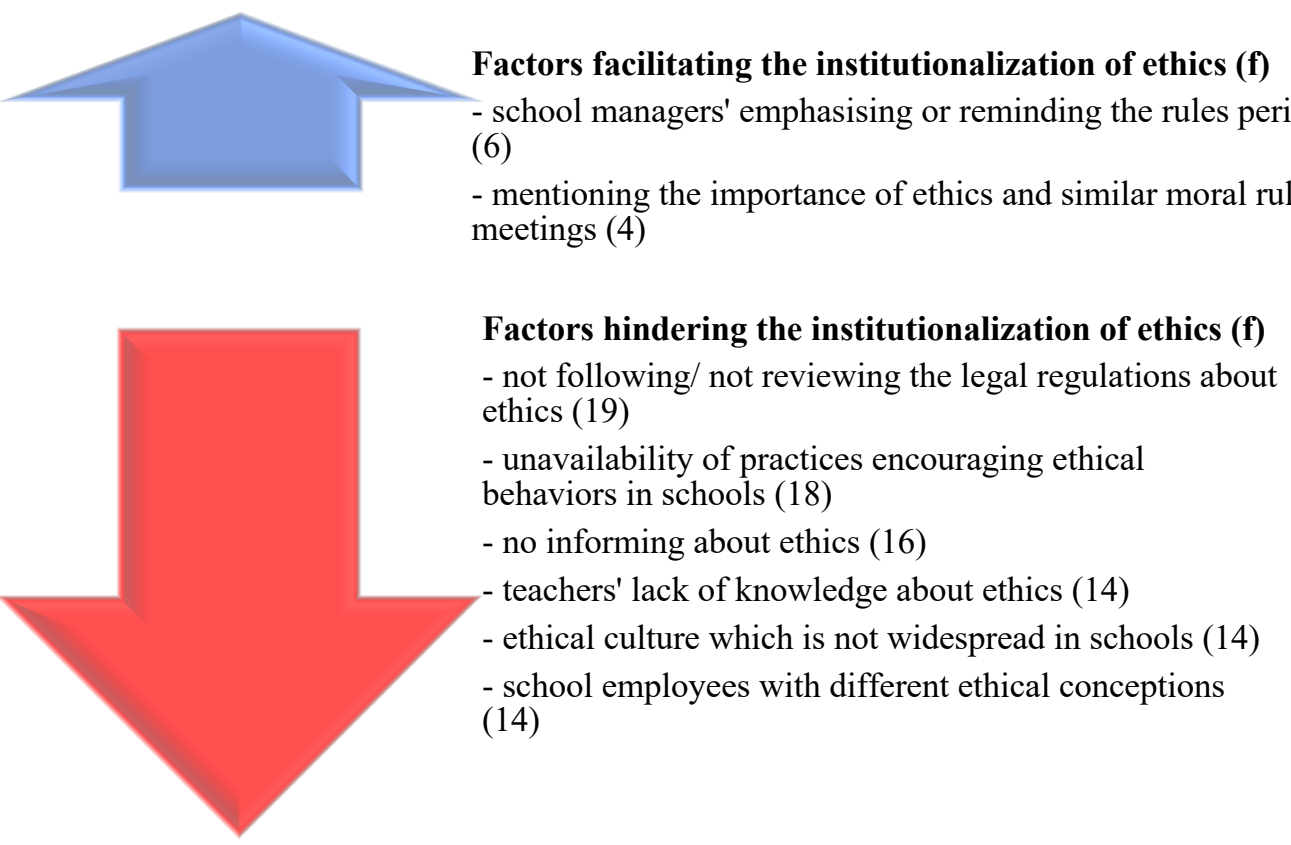

Figure 1. The sub-themes and frequencies for the theme of the institutionalization of ethics in schools

Samples for participants' views on the theme of the institutionalization of ethics in schools are as in the following:

"I have not read the regulation on ethics. I don't know what exactly ethics is and what teachers' limits of ethical behavior should be. I have not received any training in ethics throughout my professional life. Neither, have I researched or read about ethics. There was no organized culture of ethics in our school or in other schools I had worked. I have not come across ethical rules with certain limits and that do not change from person to person. If there are any, they are not known in the school. Everybody tries to implement his/her own conception of ethics." PS1.

"No! I haven't received any training in ethics. But I personally consider ethics important and I am interested in it. Information ethics should definitely be given in schools." VHS17

"I have never seen informative work or training. There were only talks reminding the rules in meetings. There is a need for it. I think efforts should be made on promoting ethical awareness." VHS18

\section{Findings for the Theme of Factors Leading to Ethical and Unethical Behaviors}

The sub-themes and frequencies for the theme of factors leading to ethical and unethical behaviors are shown in Figure 2 below. 


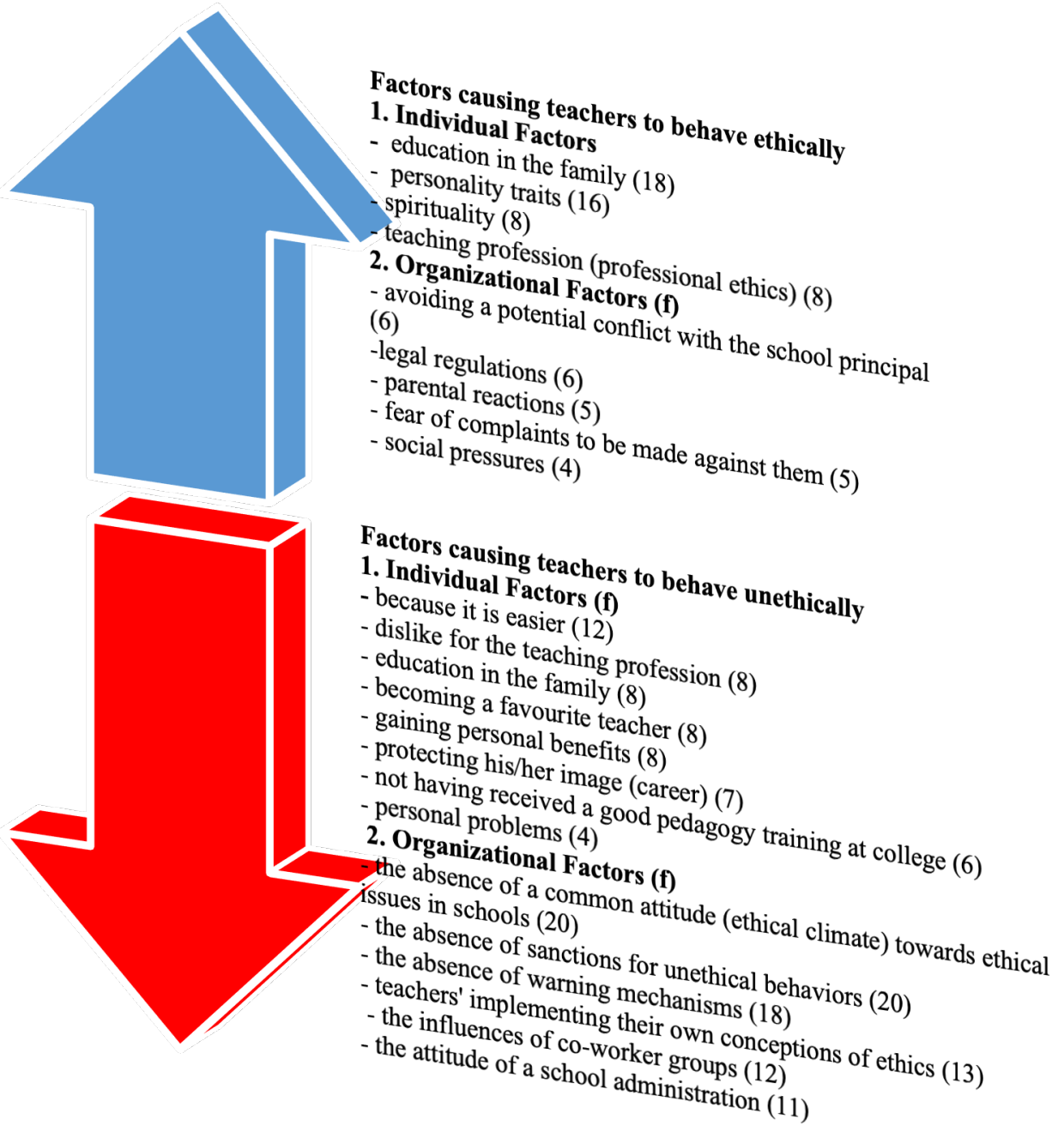

Figure 2. The sub-themes and frequencies for the theme of factors leading to ethical and unethical behaviors

As evident from Figure 2, the theme of factors leading to ethical and unethical behaviors is divided into two sub-themes as "factors causing teachers to behave ethically" and "factors causing teachers to behave unethically". Teachers' ethical behaviors can be influenced by both individual and organizational factors. According to participants, individual factors were very influential in teachers' ethical behaviors whereas organizational factors did not have same level of influence. Furthermore, punishment and threatening aspects of work relations in schools are more prominent in ethical issues than encouraging aspects. It was also found that the factors causing teachers to behave unethically were more diverse and greater in number. Therefore, it can be argued that the absence of a shared ethical conception was influential in teachers' unethical behaviors. Samples for teachers' views on the theme of factors leading to ethical and unethical behaviors are as in the following:

"Teachers begin to behave unethically if sense of justice is not a part of their personal traits. I think ethics is something that individuals have in them. There is nothing apart from their own internal sense of justice that leads them to behave ethically. We can say that perhaps the administration is a bit influential." AHS10 
is another source of motivation. I can say that intrinsic motivation is a very strong triggering factor." SS15

"Perhaps it is easier for them to behave unethically. There are not enough legal sanctions. It has been a problem for us for years. We talk about it every year but nobody obeys the rules. Legal sanctions should be increased. It is impossible if you leave it to individuals. They begin to underestimate. For example, school counsellors guide children, who commit a crime, to elude from the crime. They do it to become favorite teachers. But it is not right; it is unethical." VHS16

\section{Findings for the Theme of Reactions to Ethical and Unethical Behaviors}

The sub-themes and frequencies for the theme of reactions to ethical and unethical behaviors are shown in Figure 3.

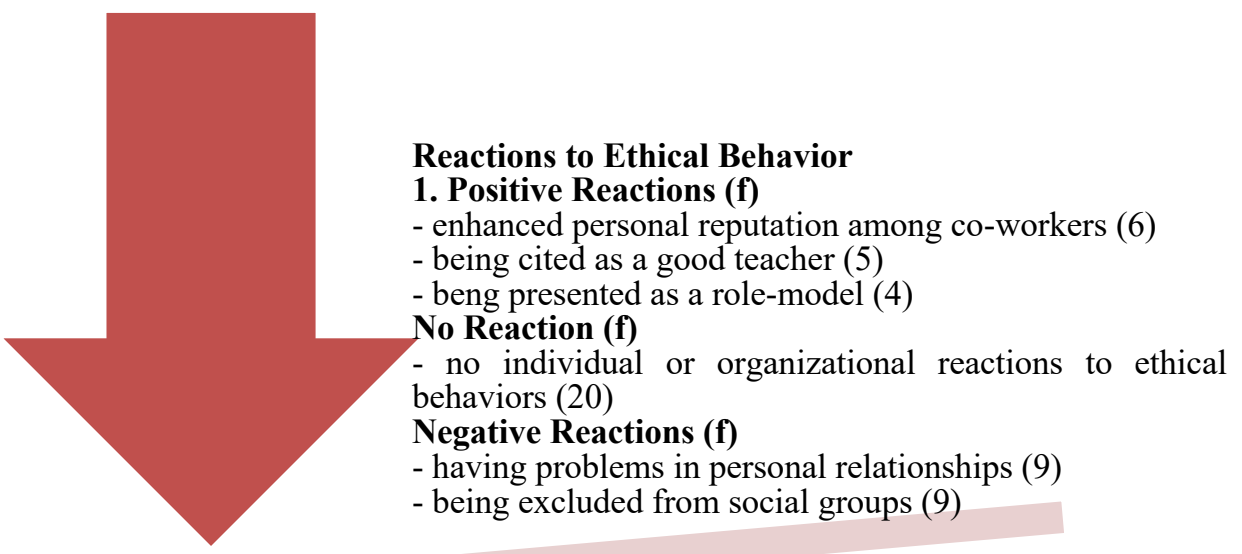

\footnotetext{
Reactions to Unethical Behavior

No Reaction (f)

- no institutional reaction to unethical behavior (20)

- no individual reaction to unethical behavior (14)

Negative Reactions (f)

- being warned by the school principal (8)

- complaint applications to ministerial or presidential

communication centres (e.g. ALO 147 or CIMER) (7)

- complaint applications to school administration (7)

- being excluded from social groups (6)

- being warned by co-workers (2)
}

Figure 3. The sub-themes and frequencies for the theme of reactions to ethical and unethical behaviors

It is clear from Figure 3 that the theme of reactions was considered in two sub-themes labelled as "reactions to ethical behaviors" and "reactions to unethical behaviors". According to the findings, teachers displaying ethical behaviors are not rewarded officially, but are praised verbally by their colleagues and school administration and are presented as role-models for their behaviors. Participant AHS9 said in this respect, "our school principal often praises such teachers in meetings. He mentions the teachers by their names, describes their behaviors as very nice and talks of them nicely", while SS12 said, "they are appreciated by teachers and 
administrators, but they are mostly not rewarded and neither are they isolated." Some of the participants, however, stated that behaving ethically put teachers into more trouble. They said that there were no institutional reactions to unethical conducts and therefore teachers displaying such behaviors usually did not receive any reaction. At this point, participant PS3 said, "the school doesn't have an institutionalized reaction to disturb them and to make them revise their behaviors." On the other hand, some of the participants said that teachers displaying unethical behaviors were warned by the school principal and teachers. In some cases, they were isolated by other teachers or reported to higher offices. While participant PS1, for instance, said, " $a$ teacher can be isolated by his or her friends when he or she behaved unethically or can be left alone"; VHSÖ17 said, "very few teachers dare to warn their colleague who behaves unethically. I myself always warn them."

\section{Findings for the Theme of Ethical Consensus}

The sub-themes and frequencies for the theme of ethical consensus in schools are shown in Figure 4.

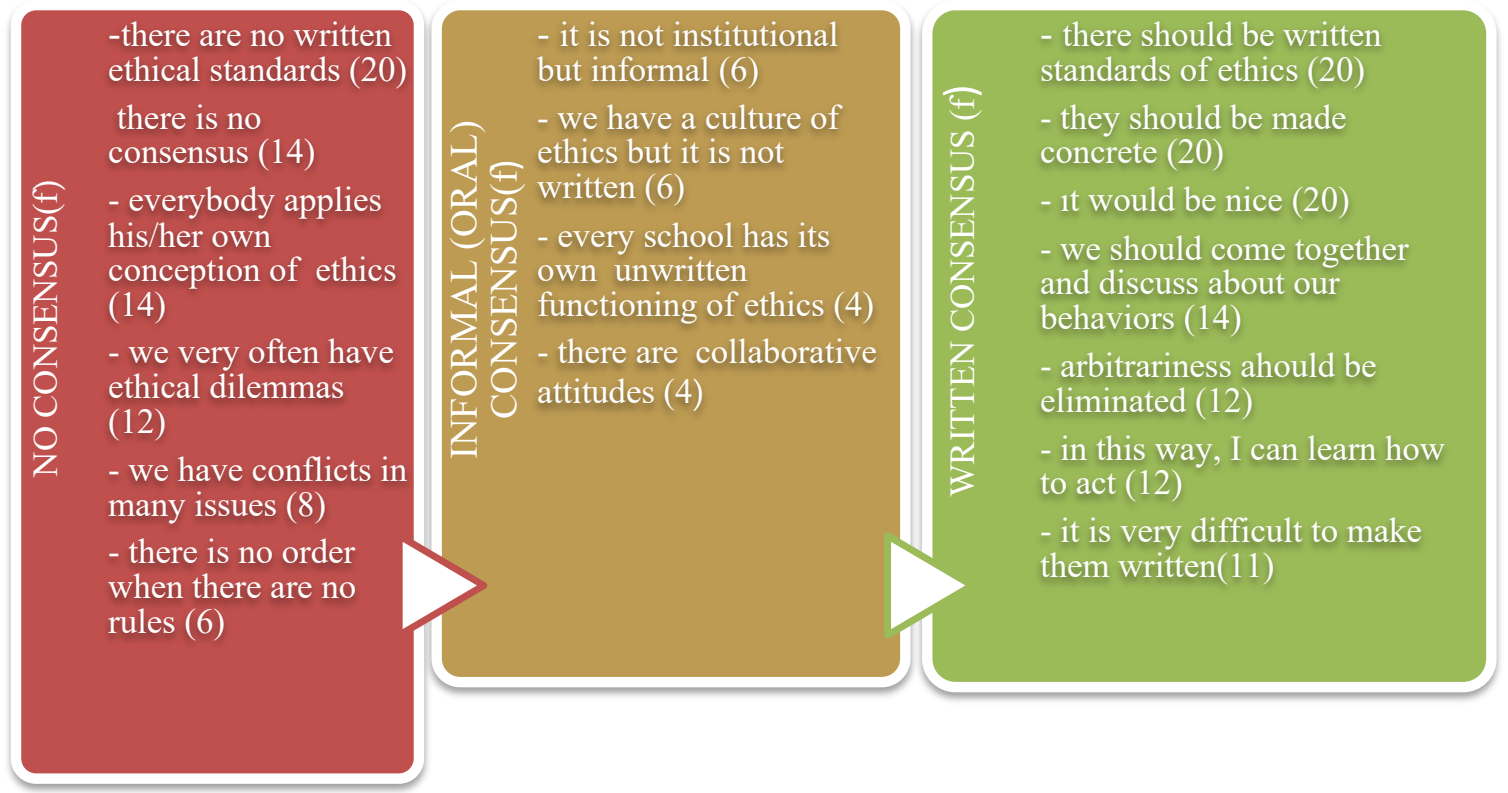

Figure 4. The sub-themes and frequencies for the theme of ethical consensus

Figure 4 makes it clear that there was predominantly no ethical consensus in participants' schools. Thus, as stated by the participants, everybody tried to apply his/her own conception of ethics, and there were ethical dilemmas and conflicts in schools where ethical consensus was not available. Participants tried to cope with dilemmas through informal relations since there were no written ethical rules in their schools, which in turn might cause the institutionalization of unethical behaviors. Yet, it was found that participants had demands for setting written standards of ethics. In other words, it can be said that the teachers were well aware of the fact that written ethical standards were required to cope with the problems they encountered. Some of the samples for the participants' views about the theme of ethical consensus were as in the following:

"... It would be better if there was written ethical consensus in school. Then, differences in interpretation can decrease; but it is very difficult to form ethical behaviors or to correct them." PS5 
"Organizations have their own unwritten rules. You can express yourself more easily in some schools while you express yourself in more difficulty in some schools. Every school has its own unwritten functioning. Everybody becomes aware of it over time. They also try to obey the rules. I think ethics also has its own unwritten rules. " AHS8

"We have no ethical consensus in our school. We feel its absence. It would be nice if the teachers and administrators negotiated about what ethical behaviors should be like. I don't know, perhaps ethical issues are written down; but implementation should not be left to individuals. Consensus will eliminate arbitrariness; but teachers cannot make evaluations about whether their behavior is ethical or not because there are no standards..." SS12

\section{Discussion and Conclusion}

Based on the research findings, we argue that there are no systematic efforts for institutionalizing ethics in schools. It was found that the influences of legal regulations, issued by MoNE to create ethical cultures in schools, on employees and school settings were limited and teachers mostly did not read the legal texts concerning ethics and did not have adequate knowledge about ethics.

Explicit institutionalization efforts should be completed first to achieve the institutionalization of ethics. The first stage of explicit institutionalization is to transform ethical principles and codes into written rules, such as regulations and directives (Aydın, 2012; Lee, Grace, Sirgy, Singhapakdi \& Lucianetti, 2018). However, it was found that ethical regulations and directives, issued by MoNE, did not have sufficient effects on the institutionalization of ethics. This issue has also been highlighted by the previous studies in the related literature. In this respect, Acar (2000) state that the most important functions of such formal structures are to develop organizational policies to institutionalize ethics, to implement and manage them in the light of ethical principles, and to solve ethical problems. Similarly, Koç (2017) claimed that it is necessary to establish ethical committees and mechanisms to reward ethical behaviors and punish misconducts for the institutionalization of ethics in schools. We argue that, this might be due to the fact that every school has its own culture. Therefore, the legal regulations, issued by MoNE, should be made visible at school settings. In addition, we argue that setting schoollevel ethical principles and codes by employees may contribute to the institutionalization of ethics in schools. Besides, formal structures, such as ethics committee, which will control the implementation of ethical principles and codes in schools and periodically evaluate the updates in these principles and codes, are also needed.

It was also found that individual factors, such as education in the family and personality traits, were more influential on teachers' ethical behaviors than organizational factors, such as legal regulations and avoiding conflicts with an administrator. It was also evident that the threatening aspects of organizational factors came into prominence in ethical issues, rather than the encouraging aspects. On the other hand, organizational factors, such as weak ethical climate and the absence of sanctions were more influential in teachers' performing unethical behaviors than individual factors, such as taking the easier way out and dislike for teaching profession. As is clear, the participants mostly made moral judgements on the basis of their moral identity and moral awareness that they had formed through previous trainings and experiences. This finding is predominantly consistent with the results of previous studies. For instance, Detert, Trevino and Sweitzer (2008) claimed that cognitive factors, such as ability for empathy and moral personality, could reduce the probability of moral disengagement and promote ethical behaviors. On the contrary, immoral personality traits, such as taking the easy way out, 
pragmatism and selfishness, may increase the probability to display unethical behaviors.

Furthermore, as clear from the findings, teachers predominantly made personal efforts to behave ethically in organizational environments, which were mostly inclined to the institutionalization of unethical behaviors rather than ethical ones. The negative effects of such environments have also been revealed in previous studies. They can create ethical climates where ethical violations can be made without breaching social norms and negative results can be considered attractive. In other words, employees are likely to use moral disengagement and act unethically without having internal conflicts or shame in unethical climates regardless of the positive effects of their moral awareness and identity (Farnese, Tramontano, Fida \& Paciello, 2011). It is because career and financial expectations in business circles make conflicts of interest between employees inevitable (Amundsen \& Pinto, 2009; Demmke \& Moilanen, 2011). It may be said that teachers engaging in ethical conducts may have difficulty competing with teachers, who do not play by the rules, in schools where ethics has not been institutionalized yet, and their behaviors may shift to the domain of unethicality over time. In fact, as Trevino et al (2006) stated, teachers can see unethical behaviors as a way out in some cases.

One of the most significant results of this study was that there was a tendency to remain unresponsive or react negatively to ethical behaviors in schools, whereas no institutionalized reaction was detected to teachers displaying unethical behaviors. Teachers with unethical behaviors either receive no reactions or they are rarely warned by school administration and teachers, isolated by their colleagues or reported to higher offices. This finding is largely consistent with the results of previous studies. For instance, Van Gils and Venus (2017) found that work stress stemming from conflicts with colleagues could increase in parallel to the increase in the frequency of ethical behaviors. As seen, for the institutionalization of ethics in schools, there is a need for an ethical climate, where ethical rules and punishment/reward system are applied fairly (Brown \& Treviño, 2006; Treviño \& Weaver, 2003), since employees, who think they are treated unfairly, may resort to unethical behaviors to balance the situation. Furthermore, employees, who have problems due to their ethical behaviors, tend not to repeat their behaviors. On the other hand, employees may be inclined to repeat their unethical behaviors in cases where unethical behaviors are ignored or not punished fairly (Hosmer, 1987; Treviño, Weaver, Gibson \& Toffler, 1999). That is to say, unethicality rather than ethicality should be expected to be institutionalized in organizations where employees are harmed due to their ethical behaviors and do not have any problems due to their unethical behaviors. For this reason, we argue that there is a need to reconsider issues, such as organizational culture, ethical climate, organizational socialization and an administration's approach towards ethical and unethical behaviors in schools where unethicality is on the way to be institutionalized.

Participants of this study thought that there was no ethical consensus about what to do in case of unethicality predominantly due to the existence of multiple ethical sub-groups in schools. This finding is largely consistent with the results of previous studies. At this point, Schnebel and Bienert (2004) pointed out that ethical consensus cannot be possible in cases where organizational stakeholders do not have a shared understanding about what is good and what is right. Similarly, Adams, Tashcian and Shore (2001) state that the ethical climate of an organization should be improved in a way to encourage ethical behaviors to reach ethical consensus. It occurs in cases where an ethical climate is an indispensable part of an organizational culture. An organizational culture supporting a strong ethical climate can socialize new members by inculcating shared values (Adams, Tashchian \& Shore, 2001). Accordingly, we claim that each new teacher joining a school where ethics is not 
institutionalized yet and unethicality is dominant in organizational climate will have difficulty in preserving his/her ethical courage no matter how high his/her ethical awareness is.

On the other hand, as implied by the findings, although each school has a different culture that restricts the effects of legal regulations issued by MoNE, those cultures are not thought to be strong enough to assimilate the sub-cultures of informal groups. Teachers try to resolve ethical dilemmas through informal relations since an ethical consensus is not available. Similarly, Bakioğlu and Koç (2017) concluded that organizational behaviors are usually shaped by ethical understanding of a group or groups (administrators, teachers, students or parents) that have the power in a school. This also leads to the institutionalization of unethical behaviors. However, teachers also pointed out that they needed written ethical standards to cope with the problems they encountered, because ethics mostly concentrates on decisions made in grey areas (Sims, 2003). The more the consensus, which is the determinant of the decisions to be made in those areas, is reached on ethical principles and standards, the more ethics is institutionalized, and employees feel secure. As the institutionalization of ethics increases, teachers are motivated to display ethical behaviors, they know how to behave in uncertain situations, and they become more consistent and more decisive about determining what is right and wrong. The institutionalization of ethics can also bring the autocratic power of administrators under control by promoting rule-governed behaviors (Aydın, 2012).

\section{Theoretical and Practical Implications}

This study contributes to the literature of educational sciences and educational administration in several aspects. To begin with, it is one of the first studies conducted in relation to the institutionalization of ethics in school environments. It also demonstrated that the concepts of explicit and implicit institutionalization, which were developed for noneducational organizations, could also be used to describe a school environment. It can also be said that classifications made for the factors causing ethical and unethical behaviors, which were also developed for non-educational organizations, could be adapted to educational organizations.

Another theoretical contribution of this study is to have revealed that the institutionalizing effects of central legal regulations about ethics can be limited since each school has a different culture. It also demonstrated that school cultures may not be strong enough to assimilate the sub-cultures of informal groups. That is to say, we argue that political relations within schools can shape the institutionalization of ethical or unethical behaviors. This can answer the question of why we still encounter unethical behaviors, while ethics in educational organizations is a frequently researched subject.

The results obtained in this study indicated that there may be an inclination towards the institutionalization of unethical behaviors rather than ethical ones in schools. There are certain strategies that administrators and teachers can use to reverse this inclination. First, school administrators can be recommended to display ethical leadership. Emphasis laid on ethical values on every occasion by administrators can increase ethical awareness in schools. Administrators' apparent approval of ethical standards and obliging all the school staff, including themselves, to apply them will certainly encourage the institutionalization of ethics. Yet, verbal approval and support may not be adequate for the process of institutionalization, since participants predominantly stated that organizational factors were usually inadequate to promote ethical behaviors and teachers behaving unethically did not receive any organizational reaction. Therefore, in making the legal regulations issued by MoNE visible in schools, it can 
be recommended that ethical goals and rules be set at the school level and directives be issued to determine the procedures to follow when misconduct occurs. Findings also indicated that there was predominantly no ethical consensus in participants' schools. In this regard, ethical contracts could be made in each school with teachers to include them in this process and to reach a consensus throughout the school. Involving teachers in administrative decisions as much as possible can strengthen the consensus environment and remove moral doubts about decisions due to multiple moral questioning.

According to the findings, organizational factors were not as influential as individual ones in the process of institutionalization of ethics. For this reason, ethical committees, specific to each school, could be formed to enable school stakeholders to observe the application of those practices. Those structures can also play roles in resolving the controversies about grey areas causing ethical dilemmas. A balanced and moderate punishment/reward system can be used to encourage ethical behaviors and prevent misconducts. Yet, care should be taken not to make rewards so ordinary as to avoid reducing the effects of ethical behaviors and to make punishments so light as to avoid rendering unethical behaviors attractive. It is possible for ethical behaviors to be institutionalized when ethical behaviors are supported, and unethical behaviors are handled appropriately. Setting out from the fact that unethical actions are more frequently seen in competitive and pressurizing tasks, it is recommended that employees be monitored closely in such situations.

Finally, as indicated in the findings section, participants were found to behave ethically mostly due to individual factors. Individual factors should also be reinforced to achieve implicit institutionalization, since the ability of ethical values to shape moral judgements is closely related to the ethical awareness of employees, in other words, their internalization of ethical values and making them a part of their personality. Therefore, training programs can be organized to raise the ethical awareness levels of employees. It can be recommended that those programs should be designed in a way to include not only the knowledge of what is right or wrong, but also the probable effects of unethical behaviors on other employees and schools.

\section{Limitations and Further Research Implications}

This is a qualitative study conducted with a small group of participants working in state schools in Istanbul. For this reason, the results may not be generalized to larger samples and private schools. It can also be recommended that future studies are conducted using quantitative research methods and with larger samples. Samples can be chosen from cities of different sizes for such studies. Studies to be conducted in private schools can also exhibit the current status of the institutionalization of ethics and factors influential in this process in those organizations.

The relationships between ethical and unethical leadership, explicit institutionalization and implicit institutionalization can be investigated to describe the process of the institutionalization of ethics accurately. In addition to the organizational consequences of the institutionalization process, individual consequences, such as psychological well-being and job satisfaction, can be researched. The applicability of ethical rules in a school environment and the potential effects of concepts, such as political skill, can be demonstrated by analysing the role of intraorganizational political relationships in the process of institutionalization of ethical or unethical behaviors. 


\section{Acknowledgements}

The summary of this study was presented in 3'rd International Symposium of Education and Values (ISOEVA) (2019)

\section{References}

Acar, A.G. (2000). Etik değerlerin kurumsallaştırılması üzerine bir araştırma [A study on the institutionalization of ethical values]. (Unpublished master thesis). İstanbul Üniversitesi, Sosyal Bilimler Enstitüsü, İstanbul.

Adams, J. S., Tashchian, A., \& Shore, T. H. (2001). Codes of ethics as signals for ethical behavior. Journal of Business Ethics, 29(3), 199-211.

Altınkurt, Y., \& Yılmaz, K. (2011). Öğretmen adaylarının öğretmenlerin mesleki etik dış1 davranışlar ile ilgili görüşleri [Prospective Teachers' Views about Teachers' Occupational Unethical Behaviors]. Mehmet Akif Ersoy Üniversitesi Eğitim Fakültesi Dergisi- Mehmet Akif Ersoy University Journal of Education Faculty, 11(22), 113 128.

Amundsen, I., \& Pinto, V. (2009). Public sector ethics. Compendium for teaching at the Catholic University of Angola (UCAN), Luanda: The Catholic University of Angola.

Arastaman, G., Fidan, İ. Ö., \& Fidan, T. (2018). Nitel araştirmada geçerlik ve güvenirlik: Kuramsal bir inceleme [Validity and reliability in qualitative studies: A theoretical review]. YYÜ Eğitim Fakültesi Dergisi- YYU Journal of Education Faculty, 15(1), 3775.

Ashforth, B. E., \& Anand, V. (2003). The normalization of corruption in organizations. Research in Organizational Behavior, 25, 1-52.

Aydın Pehlivan, İ. (2012). Yönetsel mesleki ve örgütsel etik [Administrative professional and organizational ethics]. Ankara: Pegem Yayınc1lık.

Babbie, E. R. (2006). The practice of social research. Belmont: Wadsworth.

Bakioğlu, A. \& Koç, M.H. (2017). Lise öğretmenlerinin mesleki değerlere ilişkin görüşlerinin çeşitli değişkenler açısından incelenmesi [A study of high school teachers views on professional values in terms of different variables]. Ĕ̈itimde Nitel Araştırmalar Dergisi - Journal of Qualitative Research in Education, 5(3), 270-296

Balc1, A. (2013). Sosyal bilimlerde araştırma: Yöntem, teknik ve ilkeler [Research in social sciences: Methods, techniques and principles] (Genişletilmiş 10. Baskı). Ankara: PegemAkademi.

Ball, S. J. (2012). The micro-politics of the school: Towards a theory of school organization. New York, NY: Routledge.

Bandura, A. (1999). Moral disengagement in the perpetration of inhumanities. Personality and Social Psychology Review, 3(3), 193-209.

Blase, J. J. (2000). The teachers' political orientation vis-a-vis the principal: The micropolitics of the school. In Stephen J. Ball (Ed.), Sociology of education: Major themes (pp. 12321249). New York, NY: Routledge Falmer.

Blasi, A. (1999). Emotions and moral motivation. Journal for the Theory of Social Behaviour, 
29(1), 1-19.

Booth, P., \& Schulz, A. K. D. (2004). The impact of an ethical environment on managers' project evaluation judgments under agency problem conditions. Accounting, Organizations and Society, 29(5-6), 473-488.

Brown, M. E., \& Treviño, L. K. (2006). Ethical leadership: A review and future directions. The Leadership Quarterly, 17(6), 595-616.

Chiu, R. K. (2003). Ethical judgment and whistle blowing intention: Examining the moderating role of locus of control. Journal of Business Ethics, 43(1-2), 65-74.

Cook, A., \& Glass, C. (2014). Above the glass ceiling: When are women and racial/ethnic minorities promoted to CEO? Strategic Management Journal, 35(7), 1080-1089.

Creswell, J. W. (2007). Qualitative inquiry and research design: Choosing among five approaches. Thousands Oaks, CA: SAGE Publications, Inc.

Datnow, A. (2013). Gender politics in school reform. In N. Bascia \& A. Hargreaves (Eds.), The sharp edge of educational change: Teaching, leading and realities of reform (pp. 131155). New York, NY: Routledge.

Demmke, C. \& Moilanen, T. (2011). Effectiveness of good governance and ethics in central administration: evaluating reform outcomes in the context of the financial crisis. Luxembourg: European Institute of Public Administration.

Denzin, N. K., \& Lincoln, Y. S. (2005). The Sage handbook of qualitative research (3rd Ed.). Thousand Oaks, CA: Sage.

Detert, J. R., Treviño, L. K., \& Sweitzer, V. L. (2008). Moral disengagement in ethical decision making: a study of antecedents and outcomes. Journal of Applied Psychology, 93(2), 374.

Eisenberg, N. (2000). Emotion, regulation, and moral development. Annual Review of Psychology, 51(1), 665-697.

Farnese, M. L., Tramontano, C., Fida, R., \& Paciello, M. (2011). Cheating behaviors in academic context: Does academic moral disengagement matter?. Procedia-Social and Behavioral Sciences, 29, 356-365.

Fritzsche, D. J. (2000). Ethical climates and the ethical dimension of decision making. Journal of Business Ethics, 24(2), 125-140.

Gino, F., \& Bazerman, M. H. (2009). When misconduct goes unnoticed: The acceptability of gradual erosion in others' unethical behavior. Journal of Experimental Social Psychology, 45(4), 708-719.

Guba, E. G. (1981). Criteria for assessing the trustworthiness of naturalistic inquiries. Educational Technology Research and Development, 29(2), 75-91.

Hosmer, L. T. (1987). Ethical analysis and human resource management. Human Resource Management, 26(3), 313-330.

Kahneman, D. (2003). Maps of bounded rationality: Psychology for behavioral economics. American Economic Review, 93(5), 1449-1475.

Kohlberg, L. (1969). Stage and sequence: The cognitive developmental approach to socialization. In D. A. Goslin (Ed.), Handbook of socialization theory (pp. 347-480). Chicago, ILL: Rand McNally. 
Knafl, K. A., \& Howard, M. J. (1984). Interpreting and reporting qualitative research. Research in Nursing \& Health, 7(1), 17-24.

Koç, M.H. (2017). Lise öğretmenlerinin kişisel ve mesleki değerlere ilişkin görüşlerinin çeşitli değişkenler açısından incelenmesi [The examination of the opinions of high school teachers on personal and professional values in terms of different variables]. (Unpublished doctoral dissertation). İstanbul Sabahattin Zaim University, Institute of Social Science, İstanbul.

Koonmee, K., Singhapakdi, A., Virakul, B., \& Lee, D. J. (2010). Ethics institutionalization, quality of work life, and employee job-related outcomes: A survey of human resource managers in Thailand. Journal of Business Research, 63(1), 20-26.

Lee, D. J., Grace, B. Y., Sirgy, M. J., Singhapakdi, A., \& Lucianetti, L. (2018). The effects of explicit and implicit ethics institutionalization on employee life satisfaction and happiness: The mediating effects of employee experiences in work life and moderating effects of work-family life conflict. Journal of Business Ethics, 147(4), 855-874.

Long, D. M., \& Rao, S. (1995). The wealth effects of unethical business behavior. Journal of Economics and Finance, 19(2), 65-73.

Marta, J. K., Singhapakdi, A., Lee, D. J., Sirgy, M. J., Koonmee, K., \& Virakul, B. (2013). Perceptions about ethics institutionalization and quality of work life: Thai versus American marketing managers. Journal of Business Research, 66(3), 381-389.

Miles, M. B., \& Huberman, A. M. (1994). An expanded sourcebook: Qualitative data analysis (Second edition). Thousand Oaks, Ca: Sage Publications.

Morse, J. M. (1991). Strategies for sampling. In: J. M. Morse (Ed.). Qualitative Nursing Research: A Contemporary Dialogue, (pp. 127-145). London: Sage Publications.

Reed, M. S., Evely, A. C., Cundill, G., Fazey, I., Glass, J., Laing, A., ... \& Stringer, L. C. (2010). What is social learning? Ecology and Society, 15(4), 1-10.

Schnebel, E., \& Bienert, M. A. (2004). Implementing ethics in business organizations. Journal of Business Ethics, 53(1-2), 203-211.

Shenton, A. K. (2004). Strategies for ensuring trustworthiness in qualitative research projects. Education for Information, 22(2), 63-75.

Sims, R. R. (2003). Ethics and corporate responsibility: Why giants fall. Westport: Greenwood Publishing.

Singhapakdi, A., \& Vitell, S. J. (2007). Institutionalization of ethics and its consequences: A survey of marketing professionals. Journal of the Academy of Marketing Science, 35(2), 284-294.

Thau, S., Derfler-Rozin, R., Pitesa, M., Mitchell, M. S., \& Pillutla, M. M. (2015). Unethical for the sake of the group: Risk of social exclusion and pro-group unethical behavior. Journal of Applied Psychology, 100(1), 98-113.

Toprakçı, E., Bozpolat, A. G. E., \& Buldur, A. G. S. (2010). Öğretmen davranışlarının kamu meslek etiği ilkelerine uygunluğu [The congruence of teacher behaviors with the principles of public professional ethics]. E-Uluslararası Eğitim Araştırmaları DergisiE-international journal of educational research, 1(2), 35-50.

Trevino, L. K. (1986). Ethical decision making in organizations: A person-situation 
interactionist model. Academy of Management Review, 11(3), 601-617.

Treviño, L. K., \& Weaver, G. R. (2003). Managing ethics in business organizations: Social scientific perspective. Redwood City, CA: Stanford University Press.

Treviño, L. K., Weaver, G. R., Gibson, D. G., \& Toffler, B. L. (1999). Managing ethics and legal compliance: What works and what hurts. California Management Review, 41(2), 131-151.

Treviño, L. K., Weaver, G. R., \& Reynolds, S. J. (2006). Behavioral ethics in organizations: A review. Journal of Management, 32(6), 951-990.

Tufford, L., \& Newman, P. (2012). Bracketing in qualitative research. Qualitative Social Work, 11(1), 80-96.

Van Gils, S., \& Venus, M. (2017). The burden of ethics: Moral identity determines how ethical leadership relates to employee stress. In Güçlü Atınç (Ed.), Academy of management proceedings (2017/1) (p. 13934). Briarcliff Manor, NY: Academy of Management.

Vitell, S. J., \& Singhapakdi, A. (2008). The role of ethics institutionalization in influencing organizational commitment, job satisfaction, and esprit de corps. Journal of Business Ethics, 81(2), 343-353.

Yıldırım, A., \& Şimşek, H. (2011). Sosyal bilimlerde nitel araştırma yöntemleri [Qualitative research methods in social sciences]. Ankara: Seçkin Pub. 